\title{
ПОЛУЧЕНИЕ НИТРОФОСКИ ИЗ ЭСТОНСКИХ ФОСФОРИТОВ АЗОТНО-СЕРНОКИСЛОТНЫМ СПОСОБОМ
}

Перспективным способом производства сложных удобрений является азотнокислотная переработка фосфатного сырья. Ранее нами изучены разные варианты получения нитрофоски из эстонских фосфоритов с выделением фосфогипса [1,2].

Задачей настоящей работы стало исследование возможности переработки эстонских фосфоритов в нитрофоску по схеме без отделения сульфата кальция, используемой в промышленном масштабе в СССР на основе кольского апатитового концентрата [3].

Таблица 1

Характеристика исходных проб фосфоритного концентрата

\begin{tabular}{l|c|c}
\hline Показатели & \multicolumn{2}{|c}{ Номер образца } \\
\cline { 2 - 3 } & 1 & 2 \\
\hline Тип фосфорита & чистый & пиритовый \\
Содержание, \% & & \\
$\mathrm{P}_{2} \mathrm{O}_{5}$ & 31,8 & 28,8 \\
нерастворимого & & \\
остатка & 6,5 & 14,5 \\
Отношение, \%: & & \\
$\mathrm{CaO}: \mathrm{P}_{2} \mathrm{O}_{5}$ & 152 & 143 \\
$\mathrm{MgO}_{2} \mathrm{P}_{2} \mathrm{O}_{5}$ & 3,1 & 3,5 \\
$\mathrm{Fe}_{2} \mathrm{O}_{3}$ общ $: \mathrm{P}_{2} \mathrm{O}_{5}$ & 4,1 & 9,9 \\
в том числе: & & \\
$\mathrm{Fe}_{2} \mathrm{O}_{3}$ пиритн. $: \mathrm{P}_{2} \mathrm{O}_{5}$ & 0,8 & 8,6 \\
$\mathrm{Fe}_{2} \mathrm{O}_{3}$ непиритн. $: \mathrm{P}_{2} \mathrm{O}_{5}$ & 3,4 & 1,3 \\
$\mathrm{CO}_{2}: \mathrm{P}_{2} \mathrm{O}_{5}$ & 16,5 & 11,8 \\
$\mathrm{~F}_{2}: \mathrm{P}_{2} \mathrm{O}_{5}$ & 9,0 & 9,5
\end{tabular}

В опытах использовались образцы эстонских фосконцентратов двух разновидностей [ $\left.{ }^{4}\right]$ : чистой с месторождения Раквере (участок Кабала) и пиритовой с месторождения Маарду (табл. 1). Первая проба более качественная - она содержит больше $\mathrm{P}_{2} \mathrm{O}_{5}$ и меньше coeдинений железа, чем вторая.

В экспериментах с фосконцентратом Раквере в целях получения уравновешенного удобрения количество кислот поддерживали постоянным $\left(\mathrm{HNO}_{3}-65 \%\right.$ и $\mathrm{H}_{2} \mathrm{SO}_{4}-80 \%$ от стехиометрической нормы, рассчитанной по содержанию $\mathrm{CaO}$ в фосфорите).

При использовании маардуского фосконцентрата количество реагентов варьировали в целях получения (в соответствии с требованиями сельского хозяйства ЭССР) разных марок сложных удобрений с соотношением $\mathrm{N}: \mathrm{P}_{2} \mathrm{O}_{5}: \mathrm{K}_{2} \mathrm{O}$, равным $1: 1: 1,1: 0,7: 0,7,1: 0,5: 0,9$ и $1: 0,7: 0$. Количество $\mathrm{HNO}_{3}$ составляло $65-115 \%, \mathrm{H}_{2} \mathrm{SO}_{4}-70-75 \%$ от стехиометрической нормы (табл. 2).

\section{Методика экспериментов}

Переработку фосфоритов в нитрофоску проводили по следующей схеме, имитирующей промышленный процесс [3]:

I стадия - разложение фосфорита азотной кислотой в течение 30 мин при $50^{\circ} \mathrm{C}$;

II стадия - прибавление серной кислоты (75\% от общего количества) в течение 20 мин при повышающейся температуре $\left(60-75^{\circ} \mathrm{C}\right)$;

III стадия - подача аммиака в течение 20-50 мин до рН 2,5-3; 
Показатели процесса переработки эстонских фосфоритов в нитрофоску азотно-сернокислотным способом

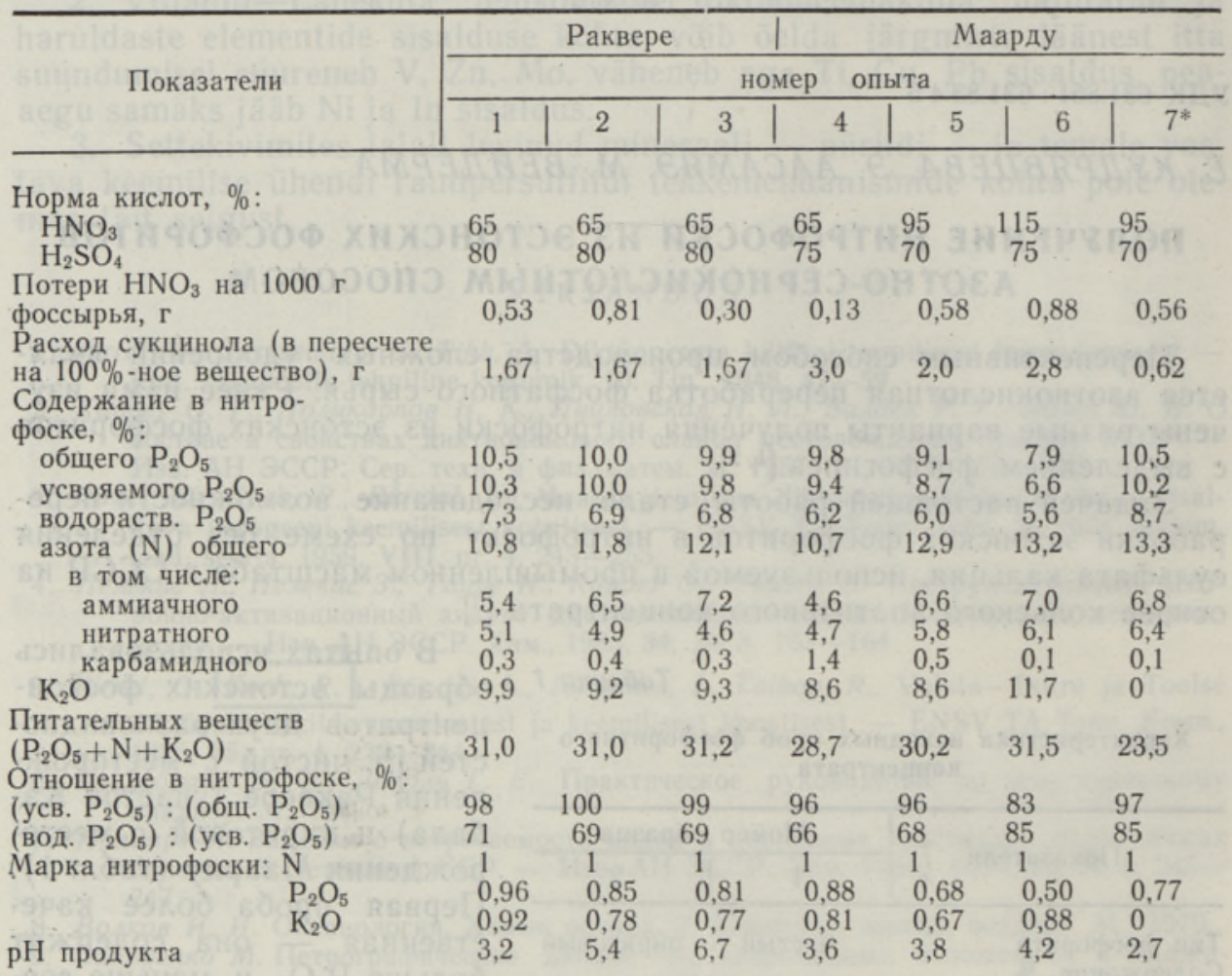

* Нитрофос.

IV стадия - одновременная подача аммиака и оставшейся части $(25 \%)$ серной кислоты в течение 5-15 мин;

$\mathrm{V}$ стадия - подача аммиака в течение $15-30$ мин до заданного значения $\mathrm{pH}$;

VI стадия - упаривание пульпы и высушивание продукта.

Продолжительность разложения фосфорита и аммонизации пульпы составляла $2-2,5$ ч, сушки $-1-1,5$ ч. Температура пульпы на III-V стадиях процесса составляла $75-85^{\circ} \mathrm{C}$.

Разложение фосфорита осуществляли в реакторе объемом 300 мл, снабженном механической лопастной мешалкой. Перед дозированием фосфорита растворяли в азотной кислоте в целях подавления выделения оксидов азота требуемое количество карбамида, составляющее, по предварительным опытам $\left[{ }^{5,6}\right], 3 \%$ от массы для фосфорита чистого типа (Раквере) и 10\% для фосфорита пиритового типа (Маарду). Реактор помещали на водяную баню с регулируемым обогревом, разложение проводили под разрежением 50-100 Па. Фосфорит (30 г) подавали в реактор в течение 2 мин с помощью герметичного дозатора, добавляя по мере надобности пеногаситель (5\%-ный водный раствор сукцинола). Серную кислоту вводили через капельную воронку.

На I и II стадиях процесса выделяющиеся из реактора газы абсорбировали последовательно: 1) 0,1 н. раствором $\mathrm{NaOH}$ для улавливания паров $\mathrm{HNO}_{3}$ и смеси $\mathrm{NO}+\mathrm{NO}_{2}$; 2) 3-6\%-ным раствором. $\mathrm{H}_{2} \mathrm{O}_{2}$ для поглощения избытка NO. Общий азот из абсорбционных растворов 
определяли отгонкой, нитритную форму азота - титрованием 0,1 н. раствором $\mathrm{KMnO}_{4}$. Это позволило раздельно определить $\mathrm{NO}, \mathrm{NO}_{2}$ и пары $\mathrm{HNO}_{3}$ в газах [5].

Аммонизацию пульпы осуществляли газообразным аммиаком, подаваемым в реактор через реометр и кругообразную распределительную трубку со скоростью 0,3 л/мин. Аммонизированную пульпу упаривали и высушивали в фарфоровой чашке на водяной бане, добавляя заданное количество хлористого калия, измельченного до крупности $-0,5$ мм. Полученный твердый продукт - нитрофоску - анализировали на содержание различных форм $\mathrm{P}_{2} \mathrm{O}_{5}$ (общего, усвояемого и водорастворимого), азота (нитратного, аммиачного и карбамидного), калия и влаги по методикам, изложенным в [7,8]. Кроме того, определяли рН продукта, используя для этого $10 \%$-ный раствор нитрофоски.

\section{Результаты экспериментов с раквереским фосфоритом}

Разложение фосфорита сопровождалось незначительным пеновыделением, расход сукцинола составлял всего лишь 1,67 г (в пересчете на $100 \%$-ное вещество) на 1000 г фоссырья (табл. 2, опыты 1-3). Температура пульпы при дозировании фосконцентрата повышалась на 17 $24^{\circ} \mathrm{C}$. При добавлении $\mathrm{H}_{2} \mathrm{SO}_{4}$ пульпа загустевала и для улучшения ее перемешивания концентрацию $\mathrm{HNO}_{3}$ снижали с 45 (опыт 1) до 40 и $35 \%$ (опыты 2 и 3 ).

При разложении фосконцентрата фосфат практически полностью переходил в раствор, при этом потери $\mathrm{HNO}_{3}$ были низкие $-0,3-0,8$ г на 1000 г фоссырья, как и в случае применения апатита [5].

Аммонизацию проводили до разного значения $\mathrm{pH}$ в целях установления допустимой степени нейтрализации без ретроградации $\mathrm{P}_{2} \mathrm{O}_{5}$.

По данным экспериментов (табл. 2), готовая нитрофоска содержит $31 \%$ питательных веществ, в том числе N $10,8-12,1 \%$, усвояемого $\mathrm{P}_{2} \mathrm{O}_{5}$ $9,8-10,3 \%$ и $\mathrm{K}_{2} \mathrm{O} 9,2-9,9 \%$. Из всего азота $50-59 \%$ было в аммиачной, $2-3 \%$ в карбамидной и остальная часть в нитратной форме. Отношение

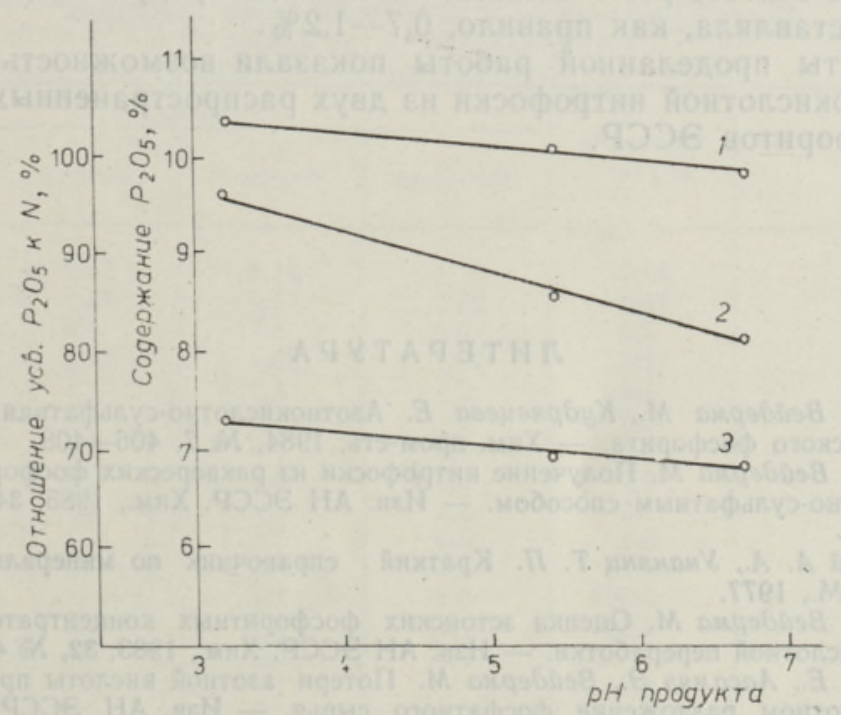

Зависимость состава нитрофоски от степени аммонизации при переработке фосконцентрата Раквере. Содержание усвояемого (1) и водорастворимого $\mathrm{P}_{2} \mathrm{O}_{5}$ (3), отношение усв. $\mathrm{P}_{2} \mathrm{O}_{5}$ K N (2). 
водорастворимого $\mathrm{P}_{2} \mathrm{O}_{5}$ к усвояемому было в пределах $69-71 \%$, а отношение усвояемого $\mathrm{P}_{2} \mathrm{O}_{5}$ к общему $\mathrm{P}_{2} \mathrm{O}_{5} 98-100 \%$. С повышением $\mathrm{pH}$ нитрофоски от 3,2 до 6,7 отношение $\mathrm{N}$ к $\mathrm{P}_{2} \mathrm{O}_{5}$ в ней изменялось от $1: 0,96$ до $1: 0,81$ с незначительной ретроградацией усвояемого и водорастворимого $\mathrm{P}_{2} \mathrm{O}_{5}$ (рисунок). Таким образом, аммонизация пульпы до pH 6-7 вполне допустима. Отношение $\mathrm{K}_{2} \mathrm{O}: \mathrm{N}$ легко регулируется изменением количества вводимого в процесс $\mathrm{KCl}$.

Результатами экспериментов показана возможность получения из раквереского фосфорита продукта, который по содержанию питательных веществ сравним с нитрофоской из ковдорского апатита [9].

\section{Результаты экспериментов с маардуским фосфоритом}

В опытах применяли $30 \%$-ную $\mathrm{HNO}_{3}$ (табл. 2, опыты 4-7). Фосфат и в этом случае практически полностью переходил в раствор. Температура пульпы при дозировании фосконцентрата повышалась на $7-10^{\circ} \mathrm{C}$. Пеновыделение не затрудняло проведение опытов, расход сукцинола составлял $1-3$ г (в пересчете на $100 \%$-ное вещество) на 1000 г фоссырья.

При использовании меньших норм $\mathrm{HNO}_{3}$ происходило загустевание пульпы в реакторе, поэтому на стадии аммонизации добавляли воду. Благодаря большой добавке карбамида потери $\mathrm{HNO}_{3}$ были низкие 0,13-0,88 г на 1000 г фосфорита. Как свидетельствуют данные анализов, они связаны лишь с выделением паров азотной кислоты и возрастали по мере увеличения нормы $\mathrm{HNO}_{3}$.

Аммонизацию пульпы осуществляли до $\mathrm{pH} 3-4,5$. Готовые образцы нитрофоски в сумме содержали $29-32 \%$ питательных веществ, а нитрофоса $-23,5 \%$. Из водорастворимого азота $51-53 \%$ находилось в аммиачной, $1-13 \%$ в карбамидной, остальная часть в нитратной форме. Отношение водорастворимого $\mathrm{P}_{2} \mathrm{O}_{5}$ к усвояемому $\mathrm{P}_{2} \mathrm{O}_{5}$ составляло свыше $66 \%$. Наблюдалась некоторая ретроградация усвояемого $\mathrm{P}_{2} \mathrm{O}_{5}$ при повышении степени аммонизации пульпы. Допустимым пределом аммонизации можно считать $\mathrm{pH} 4$. Влажность готовых продуктов (табл. 2, опыты $1-7)$ составляла, как правило, $0,7-1,2 \%$.

Результаты проделанной работы показали возможность получения азотно-сернокислотной нитрофоски из двух распространенных разновидностей фосфоритов ЭССР.

\section{Л И Т Е Р А Т У Р А}

1. Аасамяэ Э., Вейдерма М., Кудрявцева Е. Азотнокислотно-сульфатная переработка тоолсеского фосфорита. - Хим. пром-сть, 1984, № 7, 406-408.

2. Аасамяэ Э., Вейдерма М. Получение нитрофоски из раквереских фосфоритов азотнокислотно-сульфатным способом. - Изв. АН ӘССР. Хим., 1985, 34, № 3, 165169.

3. Соколовский A. А., Унанянц T. П. Краткнй справочник по минеральным удобрениям. М., 1977.

4. Аасамяэ Э., Вейдерма М. Оценка эстонских фосфоритных концентратов как сырья для кислотной переработки. - Изв. АН ЭССР. Хим., 1983, 32, № 4, 242-245.

5. Кудрявцева Е., Аасамяэ Э., Вейдерма М. Потери азотной кислоты при азотно-сернокислотном разложении фосфатного сырья. - Изв. АН ЭССР. Хим., 1986, 35 , № $1,1-6$.

6. Аасамяэ Э., Вейдерма М., Кудрявцева Е. Исследование азотнокислотного разложения тоолсеского фосфорита. - Тр. Таллин. политехн. ин-та, 1980, № 479, 3-11.

7. Методы анализа фосфатного сырья, фосфорных и комплексных удобрений, кормовых фосфатов. М., 1970, 234-238. 
8. Bremner, J. B., Keeney, D. Steam distillation methods for determination of ammonium nitrate and nitrite. - Anal. Chim. Acta, 1965, 32, N 5, 485-495.

9. Абашкина T. Ф., Шмульян Е. К., Дорошина Т. В., Леонтьева С. И. Исследование процесса получения нитрофоски из ковдорского апатитового концентрата. Тр. НИУИФа, вып. 234. М., 1979, 3-11.

Таллинский политехнический институт
Поступила в редакцию $9 / \mathrm{X} 1986$

\section{J. KUDRJAVTSEVA, E. AASAMÄE, M. VEIDERMA}

\section{NITROFOSKA VALMISTAMINE EESTI FOSFORIITIDE LÄMMASTIK-VÄÄVELHAPPELISE LAGUNDAMISE TEEL}

Katsete tulemusel on kinnitunud võimalus saada nitrofoskat kahest levinumast Eesti fosforiidi erimist (puhtast ja püriitsest), kui kasutada tehnoloogilist skeemi ilma kaltsiumsulfaadi eraldamiseta. On selgitatud happelisel lagundamisel saadud segu lubatav neutraliseerimisaste: $\mathrm{pH} 4$ Maardu ja $\mathrm{pH}$ 6-7 Rakvere fosforiidi kasutamisel. Valmisproduktid (NPK-väetised) sisaldavad $29-32 \%$ toimeaineid, kusjuures suhe $\mathrm{N}: \mathrm{P}_{2} \mathrm{O}_{5}: \mathrm{K}_{2} \mathrm{O}$ on $1: 1: 0,9, \quad 1: 0,9: 0,8$ ja $1: 0,8: 0,8$ Kabala fosforiidikontsentraadi kasutamisel ning $1: 0,9: 0,8,1: 0,7: 0,7,1: 0,5: 0,9$ Maardu fosforiidi puhul. Uldisest $\mathrm{P}_{2} \mathrm{O}_{5}$ hulgast on üle $64 \%$ vees lahustuval kujul.

Y. KUDRYAVTSEVA, E. AASAMÄE, M. VEIDERMA

\section{OBTAINING NITROPHOSKA FROM ESTONIAN PHOSPHORITES WITH A MIXTURE OF NITRIC AND SULPHURIC ACIDS}

Obtaining nitrophoska without filtering calcium sulphate, using the Estonian phosphorite concentrates from the Rakvere and Maardu deposits has been studied. The permissible step of neutralization of the mentioned compositions has been determined : $\mathrm{pH} 4$ for the Maardu and $\mathrm{pH} 6-7$ for the Rakvere phosphorite concentrates. The obtained NPK-fertilizers contained $29-32 \% \quad \mathrm{~N}+\mathrm{P}_{2} \mathrm{O}_{5}+\mathrm{K}_{2} \mathrm{O}$ and had a weight ratio of $\mathrm{N}: \mathrm{P}_{2} \mathrm{O}_{5}$ $1: 1,1: 0.9,1: 0.8,1: 0.7,1: 0.5$. Over $64 \%$ of the phosphorus obtained was in a watersoluble form. 